\title{
ULTRA HD - PRODUCTION AND CONSUMER MARKET IMPACTS
}

Chair: Leonardo dos Anjos Chaves, Gerente de Projetos em Novas Tecnologias de Transmissão, TV Globo

The panel will address the aspects of UHD content offering and its impact on the business model of digital platforms and consumer market. Join and deepen the questions:

- How do distribution technologies enable delivery of UHD content across multiplatform networks?

- What is the standardization status of UHD (HDR / WCG / HFR / Immersive Audio) technologies?

- What are the UHD technologies that increases the engagement of media consumption?

- WHO HAS UHD TV?

Speaker: Giselle de Liz - PoS Tracking Manager - GfK

This presentation will bring the UHD screens penetration figures in the Brazilian market and projections of the domestic market.

- THE CHALLENGES OF UHD DISTRIBUTION Speaker: Gustavo Marra - Vice President Solutions and Bus Dev - ATEME This speech will present an overview of the standardization of existing UHD technologies (HDR, WCG, HFR, Immersive Audio ...) and examples of UHD profiles on different digital platforms or broadcasting ( $8 \mathrm{~K}$ satellite case in Japan, $4 \mathrm{k}$ in ATSC 3.0 South Korea). It will also address impacts on HDR and HFR rates.

- UHD - SUBJECTIVE IMPACTS ON THE VIEWER Speaker: Carlos Watanabe - Director for Emerging Markets at Dolby Laboratories

This presentation will bring some studies of subjective impacts on the viewer / consumer of UHD technologies. Level of engagement, enhancements and points of attention for those who are exploring the production and distribution of these technologies both in the domestic environment (broadcasting) as cinema. 
- UHD - IMPACTS ON THE BUSINESS MODEL Speaker: André Felipe - Content Manager at Digital Platforms - Globosat

In this presentation we will analyze the impacts that the UHD content offer brings to the business models in the OTT environment and in other digital platforms. Goblosat's experience in UHD productions and future predictions (action in the 2018 World Cup).

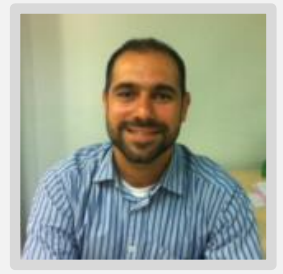

Leonardo dos Anjos Chaves, Gerente de Projetos em Novas Tecnologias de Transmissão, TV Globo

Currently, I am the Transmission Technologies Manager at TV Globo and coordinator of Technical Module in Forum SBTVD. I had the BSc in Electronic and Computing Engineering at Federal University of Rio de Janeiro (UFRJ), and MSc. of Electrical Engineering at the same university. I've got the MBA Management in Catholic University in Rio de Janeiro (PUC-Rio).

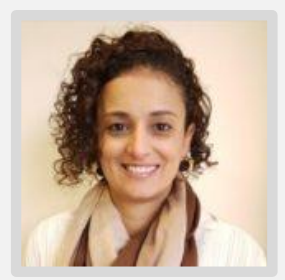

\section{Giselle de Liz - PoS Tracking Manager - GfK}

For more than 2 years she has been working at GfK as a PoS Tracking ( monitoring of durable goods sales in the retail) in brown segment, which includes Televisions, Portable Audio and Automotive Sound. Graduated in Business Administration, Post-Graduate in Market Intelligence by FIA and currently pursuing an MBA in Marketing Management from ESPM. Experience of 08 years in the durable goods industry in areas of Market Intelligence, Competitive Intelligence, and Consumer Insights in companies such as Motorola (Telecom), Samsung (TI) and Groupe SEB (ElectronicsLaptops)

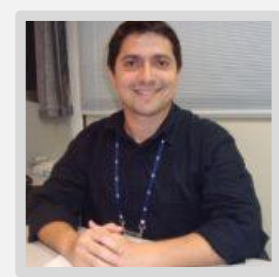

\section{Gustavo Marra - Vice President Solutions and Bus Dev - ATEME}

Graduated in Telecommunication Engineering, Post-graduated on IP Video Networks and with a MBA on Project Management, Gustavo has been working for 15 years in the media industry, currently at the position of VP of Solutions and Business Development at ATEME, being responsible for all aspects of solution Evangelism, system architecture and design, and promoting video delivery solutions to service providers and broadcasters.

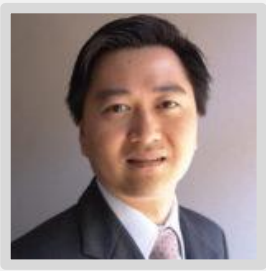

Carlos Watanabe - Director for Emerging Markets at Dolby Laboratories Carlos Watanabe is Director for Emerging Markets at Dolby Laboratories, the global leader in audiovisual entertainment technologies. For more than 50 years, Dolby has created audio, video and voice technologies that transform entertainment and communications on mobile devices, movies, the home and work.Carlos is an Electrical Engineer graduated from the State University of Campinas (UNICAMP), with an MBA from the Ross School of Business at the University of Michigan. He has more than 20 years of experience in technology, media and entertainment companies, and senior management consulting. 


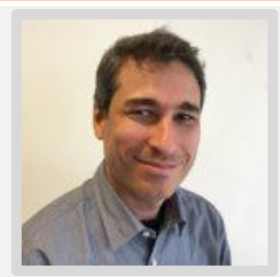

\section{André Felipe - Content Manager at Digital Platforms - Globosat}

André has been with Globosat for 22 years, and has worked in various areas of the company. In his current role, André and his team lead the acquisition, programming and distribution of the company's VOD and TV Everywhere content. André is 45 years old, is a computer engineer and has an MBA from Ibmec. 